УДК 159.91

\title{
ОБЗОР СОВРЕМЕННЫХ ИССЛЕДОВАНИЙ ПСИХОГЕНЕТИЧЕСКИХ ФАКТОРОВ АГРЕССИВНОГО ПОВЕДЕНИЯ
}

\author{
Ковш Екатерина Михайловна \\ Воробьева Елена Викторовна \\ Ермаков Павел Николаевич
}

Обзор посвящен актуальным отечественным и зарубежным исследованиям психогенетических факторов агрессивного поведения. Рассмотрены цитогенетические механизмы, обеспечивающие психическую деятельность и поведенческую активность человека, представлена концепция управляющей системы кодирования информации, указаны особенности генотип-средового взаимодействия в формировании агрессивного поведения. Дана классификация видов агрессии, рассмотрены подходы к трактовке данного понятия. Проведен анализ теорий, объясняющих природу агрессивности (фрустрачионная теория Дж. Долларда, Л. Берковии, теория социального научения А. Бандуры, теория инстинктивных влечений К. Лоренца, 3. Фрейда, биологическая теория). Описаны мозговые механизмы, лежащие в основе различных видов агрессивного поведения.

Проанализировано большое количество отечественных и зарубежных исследований, посвященных проблеме генетического детерминирования психических процессов и поведения. Представлен обзор исследований генных оснований агрессивного поведения: описаны подходы, признанные на сегодняшний день несостоятельными (теория лишней Ү-хромосомы, система «ген-признак», концепция «генов-генералистов»), а также приведены подтвержденные на сегодняшний день представления: описана роль нейромодуляторов-моноаминов (показана взаимосвязь различных форм агрессивного поведения с деятельностью медиаторных систем мозга), тестостерона; рассмотрено влияние социально-экономического статуса и факторов среды. Имеющиеся психогенетические данные описаны с точки зрения аддитивной модели развития. В челом, отмечается полигенный характер наследования агрессивности (гены, кодирующие информацию об устройстве обонятельной, гормональной, медиаторных систем являются биологическими факторами агрессии).

Представлены перспективы развития данного направления исследований - биоинформационный анализ молекулярных механизмов деятельности центральной нервной системы посредством исследования экспрессии генов в клетках мозга; приведен обзор первых результатов, полученных при помощи данного метода. 
Ключевые слова: психогенетика агрессивности, нейромедиаторные системы, моноамины, генетика поведения, молекулярная генетика, агрессивное поведение, агрессия, биологический субстрат, мозговые механизмы, хромосомные аномалии, генотип-средовое взаимодействие.

На сегодняшний день наука сделала еще один шаг вперед, продвинувшись в развитии представлений о природе психики и поведения. Стремясь к пониманию механизмов, лежащих в основе и оказывающих влияние на поведенческие реакции и психику в целом, ученые исследуют социокультурные условия жизни индивида, его этнические особенности, специфику индивидуальной среды, особенности онтогенетического развития организма, свойства и функции отделов и структур нервной системы, а также биохимические процессы, протекающие в нервной ткани.

Изучением такого сложного феномена, как психика человека и факторы, оказывающие на нее воздействие, занимаются многие науки. Особенно интересным научным направлением в данном контексте, на наш взгляд, является генетика поведения (психогенетика) - междисциплинарная наука, предметом которой выступают наследственные и средовые детерминанты вариативности психологических и психофизиологических характеристик человека [21]. В русле данной дисциплины существует следующее предположение о цитогенетических механизмах, обеспечивающих психическую деятельность и поведенческую активность: скорость и качество протекания биохимических процессов в нервной клетке и межклеточном пространстве определяется участием нейромедиаторов и нейромодуляторов, концентрация которых задается последовательностью аминокислот в кодирующих белках. Следовательно, экспрессия генов, т. е. проявление их функции в клетках мозга, является основой работы нейрона [13]. Нейроны же, образуя колонки, структурные и функциональные ансамбли, обеспечивают протекание разных видов поведенческих реакций, характер которых определяется локализацией задействованных клеток и электрическими, биохимическими процессами, протекающими в них.

В настоящее время существует предположение о наличии управляющей системы кодирования информации. В качестве таковой выступают генные сети - ансамбли координированно функционирующих генов, обеспечивающих биосинтез молекулярных, биохимических, метаболических, энергетических и структурных элементов нейрона. В 2007 г. ученые M. J. Hawrylycz, E. S. Lein и др. создали геномный атлас экспрессии генов и показали возможную связь между функциями нейронов и генными сетями [37]. Данные исследования положили начало масштабному изучению генных сетей, проводимому учеными Новосибирского университета. Предварительные выводы по результатам 
исследований таковы: «Так же как существует иерархия сетей нейронов, вплоть до глобальной нейронной сети, соответствующей мозгу и нервной системе, существует и соответствующая иерархия генных сетей. При этом генные сети отдельных нейронов, объединяясь в генные сети более крупных клеточных образований, формируют иерархию вплоть до единой генной сети мозга и нервной системы» [13, с. 3]. Участвующие в регуляции синаптической передачи гены рассматриваются как гены-кандидаты, обусловливающие наследственные особенности поведения [17].

Наибольшее распространение в психогенетике получили исследования генотип-средового взаимодействия в формировании интеллекта, темперамента, психических болезней и типов мозговых ритмов $[1,5,6,21,27]$. В последние годы, ввиду высокой актуальности проблемы деструктивного и неконтролируемого проявления агрессии в современном обществе, отечественными и зарубежными учеными все чаще исследуются генетические предпосылки разных форм агрессивного и враждебного поведения $[2,12$, $14,17,25,26,28,29,36,41,45,48,49]$. Агрессивность как свойство личности обусловливает асоциальное и криминальное поведение. В связи с этим, исследования агрессивного поведения получили распространение также в рамках генетики девиантного поведения [31, 34, 45].

Под агрессивностью сегодня принято понимать особенность индивидуальности [24], склонность личности действовать враждебно или агрессивно [19, 20]. При этом агрессия понимается как форма поведения, целью которого является оскорбление или причинение вреда живому существу, не желающему такого обращения $[4,7,19]$. В. П. Зинченко и Б. Г. Мещеряков дают такое определение агрессии: мотивированное деструктивное поведение, противоречащее нормам и правилам сосуществования людей в обществе, наносящее вред объектам нападения (одушевленным и неодушевленным), приносящее физический ущерб людям или вызывающее у них психический дискомфорт (отрицательные переживания, состояние напряженности, страха, подавленности) [10].

Нужно отметить тот факт, что на сегодняшний день агрессия рассматривается не только как форма поведения, но и как состояние (Л. Берковиц, Н. Д. Левитов, Л. Б. Шнейдер), как инстинкт (Ю. Л. Орлов), а агрессивные действия могут быть направлены на достижение значимой цели или психической разрядки, на удовлетворение или замещение блокированной потребности, на переключение деятельности (А. А. Реан). Агрессивность же может выступать как мотив (Х. Хекхаузен), черта личности или характера (К. К. Платонов) и свойство темперамента (В. С. Мерлин), определяющее при этом как ситуативные, так и устойчивые формы поведения.

По данным отечественных авторов, уровень агрессии обусловлен социальными моделями поведения, которые человек усваивает в качестве 
социокультурных норм, важнейшими из которых выступают нормы социальной ответственности [16]. При этом не всегда за агрессивным поведением скрывается высокая агрессивность личности (необходимо учитывать мотивы и обстоятельства), и не всегда агрессивность проявляется в открытом действии. Агрессивные импульсы могут подавляться волевым усилием, что часто приводит к развитию психосоматических заболеваний, или трансформироваться посредством механизмов психологической защиты, сублимироваться в творческую и спортивную деятельность и пр.

Наряду с агрессивностью, исследователи рассматривают такие взаимосвязанные понятия, как экстрапунитивность (готовность к нападению в фрустрирующих условиях), враждебность (негативная установка по отношению к окружающим), жестокость (стремление причинять боль, страдания живым существам), гнев (отрицательно окрашенный аффект, направленный против испытываемой несправедливости и сопровождающийся желанием устранить ее) [24].

Агрессию принято разделять на защитную или реактивную (ответ на угрозу), проактивную (нападение) или инструментальную (агрессивное поведение как средство для достижения иной поставленной цели), в т. ч. обученную (армия, спорт, конкурентный бизнес), мотивационную (агрессия как самоцель) и патологическую (при психических заболеваниях) [4, 7, 18, 24, 49].

Существуют такие подходы к трактовке природы агрессии, как: фрустрационная теория (Л. Берковиц, Дж. Доллард), теория социального научения (А. Бандура), теория инстинктивных влечений (К. Лоренц; агрессия как антитеза сексу и либидо - 3. Фрейд). Таким образом, агрессия - сложный механизм, многоаспектность которого проявляется в зависимости от мотива. Агрессивное поведение, направленное на удовлетворение витальных функций, способствующее социальной адаптации (Э. Фромм) и эволюционному развитию вида (К. Лоренц), считается «доброкачественной» агрессией. Деструктивное, разрушительное, жестокое поведение является примером «злокачественной» агрессии и проявляется в условиях недостаточного контроля агрессивных импульсов (Э. Фромм).

Наиболее интересной в контексте заявленной темы выступает биологическая теория агрессивного поведения. Ее предпосылки мы находим в работах древнегреческих врачей и мыслителей (Гиппократ, Аристотель), философов позднего Средневековья. Впоследствии теорию, объясняющую природу агрессии биологическими факторами, развивали Чарльз Дарвин, Чезаре Ломброзо и др.

На сегодняшний день данная теория постулирует наличие мозгового субстрата или функций, лежащих в основе агрессивного поведения. Благодаря исследованиям нейробиологов, проводившимся в прошлом веке, удалось 
обозначить роль структур лимбической системы, а именно: миндалины, гиппокампа, гипоталамуса, поясной извилины, а также таких структур, как островковая и преоптическая области коры, стриатум и пр. в формировании агрессивных реакций человека и животных. Согласно имеющимся данным, функциональные или морфологические аномалии в одной или нескольких из этих структур, повреждение связей между ними способствуют увеличению восприимчивости к чрезмерной стимуляции, что приводит к патологической импульсивной агрессии и проявлению насилия [31, 34].

Alan Siegel выделяет два основных вида агрессии, каждый из которых имеет свои мозговые механизмы. Так, хищническая агрессия, включающая в себя построение сложной программы поведения (охота), регулируется корой головного мозга и обеспечивается активностью нейронов гипоталамуса, покрышки, серого вещества околоводопроводной области и тегментальной мезенцефальной областью, продуцирующей дофамин. Эмоциональная агрессия обеспечивается работой медиальной области гипоталамуса, являющейся субстратом глутаматергической системы. Данная система запускает целый спектр вегетативных проявлений, сопровождающих реакцию оборонительной ярости [43]. Таким образом, комплекс гипоталамо-кортико-лимбической нейронной цепи, стимуляция которого приводит к патологической агрессии, запускает работу многих медиаторов, гормонов, цитокинов, ферментов и нейтрофинов [26].

В современных исследованиях изучаются различные биологические предпосылки агрессивности. Так, выраженность данной особенности личности связывают с высоким уровнем содержания гормонов (тестостерона и кортизола) и холестерина в крови, гипогликемией, гиповитаминозом A и С, органическими повреждениями головного мозга (ЧМТ, инсульты, родовые травмы и пр.) и, как их следствие, с нарушениями нервной регуляции, расстройствами вегетативной нервной системы, хромосомными мутациями и пр. [2, 9, 14, 27, 30, 35, 38, 41, 44, 47]. Однако многие из перечисленных корреляций, возможно, отражают не первичную, а вторичную детерминацию агрессивного поведения [18].

Некоторые исследовательские подходы к изучению генетических факторов поведения на сегодняшний день признаны несостоятельными:

- прямые причинно-следственные связи между «простым» геном и «сложным» поведением признаны маловероятными [2]. Следовательно, не существует «гена агрессии»: агрессивность, как и другие изучаемые свойства психики и особенности поведения, имеет полигенный характер наследования. Выделяют около 17 генов, оказывающих влияние на формирование агрессивного поведения [2, 23, 27];

- появившаяся в 2006 г. концепция «генов-генералистов», согласно которой большая часть генов, экспрессирующихся в ЦНС, участвует в модуляции 
каждого из когнитивных процессов (Y. Kovas, R. Plomin et al.), также не нашла своего подтверждения: отечественные исследователи (И. 3. Плюснина, Н. К. Попова и др.) отвергают данную точку зрения, выделяя особенности влияния различных участков генов на поведение;

- среди несостоятельных теорий, призванных объяснить генетическую природу агрессивного поведения, важно упомянуть и следующую: долгое время считалось, что наличие Y-хромосомы (в особенности - лишней) существенно повышает склонность человека к тяжелым агрессивным поступкам (насилию, убийствам). В связи с этим, проводились многочисленные исследования (П. А. Джейкобс, У. Пирс и др.) по изучению уровня агрессивности у здоровых испытуемых и лиц с хромосомными аномалиями, совершивших противоправные действия. Вопреки ожиданиям, гипотеза о наличии достоверно значимых различий в уровне агрессивности и частоте совершения противоправных действий участниками двух групп не подтвердилась (С. Чавкин, С. Шэн, Э. Хук). У лиц, имеющих лишнюю Y-хромосому, был диагностирован достоверно более высокий уровень импульсивности и низкий уровень интеллекта, что, предположительно, и толкало их на совершение преступлений, основными из которых являлись жульничество и воровство [38].

Среди подтвержденных на сегодняшний день представлений отечественных и зарубежных авторов о психогенетической природе агрессивного поведения можно выделить следующие:

1. Ученые выделяют около шести медиаторных систем головного мозга (в их числе серотонинергическая, катехоламинергическая, опиоидергическая и др.), участвующих в регуляции и контроле агрессивного поведения. Несомненной считается роль нейромодуляторов-моноаминов (серотонина, дофамина, норадреналина) в формировании индивидуальных особенностей агрессивности. Данные, полученные из многочисленных исследований, проводившихся, главным образом, на животных, свидетельствуют о том, что различные формы агрессии независимы друг от друга и находятся под относительно автономным генетическим контролем [21]. Имеется определенная нейрохимическая специфика для разных форм агрессивно-оборонительных реакций: B. Eichelman и N. B. Thoа связывают «хищническую» агрессию с деятельностью серотонинергической системы, «раздражительную» (вызванную болью) агрессию - с влиянием норадренергической системы, а «спонтанную» агрессию - с дофаминергическими воздействиями. Интересна роль опиоидергической системы: она обеспечивает контроль над проявлением агрессии, участвуя в процессах положительного и отрицательного подкрепления поведения [8]. Похожие результаты были получены благодаря серии исследований, проведенных в Новосибирском институте цитологии и генетики РАН 
под руководством академика Д. К. Беляева (2001). Ученые подтвердили тот факт, что формы агрессивного поведения у животных - агрессия хищника, межсамцовые конфликты, материнская агрессия, агрессивное поведение в ситуации страха и по отношению к человеку - находятся под контролем различных генетических механизмов [12].

В целом, функции моноаминов распределяются следующим образом:

Дофамин, химический фактор внутреннего подкрепления, активирующий компонент «центра удовольствия» головного мозга, вещество, являющееся биохимическим предшественником адреналина и норадреналина, является в достаточной мере изученным нейромедиатором. С нарушением дофаминергической системы связывают такие расстройства, как: ангедония, депрессия, деменция, патологическая агрессивность, фиксация патологических влечений, синдром персистирующей лактореи-аменореи, импотенция, акромегалия, синдром беспокойных ног и периодических движений в конечностях, паркинсонизм [9]. Агрессивность при болезни Альцгеймера связывают с геном рецептора дофамина первого типа [41], при посттравматическом стрессовом расстройстве - с геном рецептора дофамина второго типа [29].

Серотонин является медиатором мозга, регулирующим различные виды поведения и физиологические процессы (Н. К. Попова и др., 1978; С. A. Fornal, B. L. Jacobs, 1995; I. Lucki, 1998). Нейроны, продуцирующие серотонин, pacположены в гипоталамусе, гиппокампе, базальных ядрах, лобных долях коры больших полушарий, миндалине и, в соответствии со своей локализацией, выполняют функции регуляции сна, чувства голода, температуры тела, полового и агрессивного поведения, общего фона настроения и беспокойства [48].

Роль серотонина в регуляции поведения сложно переоценить. Дефицит данного нейромедиатора приводит к значительным расстройствам поведения: от незначительных заострений определенных личностных черт, таких как импульсивность, враждебность, раздражительность, склонность к насилию, - до более явных расстройств личности, таких как: заострение антисоциальных и пограничных черт личности, нарциссизм и истерические расстройства, суицидальное поведение, открытая агрессия, пароксизмы ярости, патологический гемблинг, булимия, пиромания, алкоголизм и некоторые виды токсикомании [45].

Масштабное исследование роли серотонинергической системы в регуляции поведения было проведено В. С. Науменко и коллегами на зимоспящих сусликах. Ученые подтвердили факт участия гена ключевого фермента биосинтеза 5-НТ - триптофангидроксилазы-2 в регуляции агрессивного поведения [36], а также продемонстрировали роль 5-НТ1А рецепторов в подавлении агрессии, вызванной страхом, и агрессии нападения; в механизмах зимней спячки и ассоциированной с ней глубокой гипотермии $[17,40]$. Была выявлена 
активность 5-НТ2А рецепторов в подавлении пассивно-оборонительного защитного поведения - каталепсии [40].

Показана роль генов, контролирующих синтез серотонина (SLC6A4) и дофамина (COMT), в предрасположенности к крайней форме аутоагрессивного поведения - самоубийству [21]. Другие исследования показывают взаимосвязь агрессивного поведения у людей, совершивших попытку самоубийства, с полиморфизмом промоторного участка гена, кодирующего рецептор серотонина типа 2A [46].

Особую роль в совершении тяжких преступлений, проявлении насилия у лиц с алкогольной зависимостью и психическими заболеваниями отводят S-промотору гена SLC6A4 (структурные изменения промоторного участка гена обычно влекут за собой изменения активности гена и тем самым - изменение количества кодируемого геном белка) [21].

Роль генов, контролирующих синтез нейромедиаторов-моноаминов, в предрасположенности к несуицидной агрессии можно проиллюстрировать следующим образом:

- с проявлением склонности к жестокости связывают гены ADRB2, HTR2A, DRD4;

- к раздражительности - ТРН2;

- к жестокости и раздражительности - TPH1, MAOA, SLC6A4, COMT;

- к вербальной агрессии - HTR3, ADRA2A;

- к физической агрессии - MAOA, SLC6A4, COMT;

- к общему негативизму - TPH1, SLC6A4, COMT [21, 32].

2. Гены, кодирующие информацию об организации обонятельной, гормональной, серотониновой (медиаторных) систем, являются кандидатами, обусловливающими наследственные особенности агрессивного поведения $[13,35,39,42,47]$.

3. Взаимосвязь агрессивности с высоким содержанием тестостерона в крови исследовалась многими учеными. Было доказано, что мужчины, в крови которых содержится большое количество андрогенов (половых гормонов), демонстрируют высокую склонность к преступности, аддитивному, экстремальному и активному сексуальному (большое количество половых партнеров) поведению [30]. Исследования показывают, что высокий уровень тестостерона связан с антисоциальными и криминальными формами поведения, а также с II типом алкоголизма, склонностью к психопатизации личности [44].

4. Исследование влияния социально-экономического статуса на активность серотониновой системы продемонстрировало наличие высокого уровня агрессивности при низком социально-экономическом статусе у людей с генотипами SS и LS [21, 25]. 
5. Безусловно, важную роль в развитии изучаемых признаков играет среда, но на сегодняшний день существует мнение о том, что она лишь «накладывается» на генетические различия, способствуя или препятствуя их развитию $[6,21]$.

Неадекватно высокий уровень агрессивности, как правило, связывают с хронически низкой активностью серотониновой системы. Однако в основе ее дефектности лежит взаимодействие биологических и социальных факторов на уровне молекулярных механизмов. Были проведены исследования генотип-средового взаимодействия у макак-резусов, воспитывавшихся матерями и в изоляции. Отсутствие материнской заботы усиливает агрессивность особей, гомозиготных по S-промотору гена SLC6A4, но не влияет на гомозигот LL и гетерозигот [21].

Использование методов психогенетики, в частности, близнецового метода, позволяет оценить вклад наследственных и средовых факторов в фенотипическую вариативность признака [3]. М. T. Yeh, E. F. Coccaro и К. C. Jacobson [49] провели масштабное исследование влияния роли наследственности и среды, а также половой принадлежности на предпочитаемые виды и формы агрессии (косвенная, вербальная, физическая агрессия, нападение и борьба, приступы гнева и истерики) с участием почти 3000 близнецов. Исследователи пришли к выводу о существовании двух больших факторов - общей и физической агрессии. Участие наследственности и среды в формировании перечисленных признаков, согласно полученным данным, примерно одинаковое и их распределение у мужчин и женщин достоверных различий не продемонстрировало. Эти данные подтверждают результаты, полученные ранее [28] о преобладании у мужчин наследственного компонента - предиктора косвенной, вербальной, физической агрессии и раздражительности (классификация A. Басса и А. Дарки), а также данные, полученные D. S. Cates в изучении наследственного компонента в проявлении вербальной, косвенной агрессии и раздражительности у женщин [27].

Результаты близнецовых и семейных исследований позволяют заключить, что индивидуальные различия агрессивности почти на 50 \% обусловлены наследственными факторами. Часть генов, оказывающих влияние на различия в проявлении данного параметра, является общей для разных типов агрессивного поведения и некоторых высоко наследственно детерминированных черт темперамента (эмоциональности и импульсивности) [1, 2, 5, 6]. Семейная среда не представляет собой важной предпосылки агрессивности у взрослых, а индивидуальная, напротив, объясняет не менее 50 \% ее дисперсии. В целом эти результаты сходны с данными о соотносительном вкладе генотипа и среды, полученными для других психологических свойств [1, 2]. 
O перспективах: на сегодняшний день применяется новый метод в исследовании генома человека - биоинформационный анализ молекулярных механизмов деятельности центральной нервной системы посредством исследования экспрессии генов в клетках мозга. С его помощью открыты многие молекулярные компоненты, включенные во внутриклеточные пути передачи информации от рецепторных к эффекторным структурам нейрона, исследовано химическое строение многих белков, вовлеченных в процессы межклеточной и внутриклеточной сигнализации, выявляются гены, экспрессия которых повышена в тканях мозга. Одним из крупнейших достижений последнего времени в области нейронаук является создание трехмерных атласов экспрессии генов в мозге $[13,37]$. Наиболее перспективной моделью в психогенетике является, на наш взгляд, аддитивная модель развития, согласно которой фенотип представляет собой кумулятивный продукт генотип-средового взаимодействия [23].

Роль наследственности и среды - тема, которая будет изучаться, повидимому, еще не одно столетие, т. к. перспективы научных открытий имеют большой масштаб. Изучение генетических предпосылок агрессивного поведения актуально ввиду возможностей, которые нам способны предоставить данные исследования. Уменьшение вспышек агрессии от семейных ссор до террористических актов и военных конфликтов, нивелирование деструктивных последствий проявления «злокачественной» агрессии посредством ее профилактики - вот основные цели проводимых исследований, достижение которых, возможно, существенно повысит уровень и качество жизни современного человека, сделает более безопасной среду его существования [33].

\section{Литература}

1. Алфимова М. В., Трубников В. И. Генные основы темперамента и личности // Вопросы психологии. - 2000. - № 2. - С. 115-118.

2. Алфимова М. В., Трубников В.И. Психогенетика агрессивности // Вопросы психологии. - 2000. - № 6. - С. 112-123.

3. Бондаренко В. В., Воробьева Е. В. История формирования близнецового метода в психологии // Северо-Кавказский психологический вестник. 2006. - № 4. - С. 151-153.

4. Бэрон Р., Ричардсон Д. Агрессия. - СПб.: Питер, 2001. - 352 с.

5. Воробьева Е. В. Интеллект и мотивация достижения: психофизиологические и психогенетические предикторы. - М.: КРЕДО, 2006. - 288 с.

6. Воробьева Е. В. Психогенетическое исследование взаимосвязи темперамента и мотивации достижения // Известия высших учебных заведений. Северо-Кавказский регион. Общественные науки. - 2006. № 3. - С. 110-111. 
7. Коннор Д. Агрессия и антисоциальное поведение у детей и подростков. Исследования и терапевтические стратегии. - М.: Олма-медиа групп, 2005. - 286 c.

8. Кудрявцева Н. Н. Агрессия: от концепции К. Лоранца к современным представлениям // Природа. - 2008. - № 9. - С. 60-63.

9. Левин Я. И. Нейрохимическая медицина. Часть 1. Церебральные дофаминергические системы // Современная терапия психических расстройств. - 2008. - № 1.

10. Мещеряков Б. Г., Зинченко В. П. Большой психологический словарь. - СПб.: Прайм Еврознак, 2006. - 672 с.

11. Михайлова О. Ю. Психологические механизмы криминальной сексуальной агрессии: дисс. ... докт. психол. наук. - Ростов н/Д., 2001.

12. Михайлова Т. И. Психогенетические предпосылки агрессивности // Вестник СумДУ. Серия «Медицина». - 2012. - № 1.

13. Орлов Ю. Л., Вишневский О. В., Витяев Е. Е. и др. Биоинформационный анализ экспрессии генов в клетках мозга // Материалы XV Всероссийской научно-технической конференции «Нейроинформатика-2013». Москва, 2013.

14. Павленко В. Б., Калашник О. А. Нейроэтология и нейрофизиологические корреляты агрессивности // Ученые записки Таврического национального университета им. В. И. Вернадского. - 2005. - Т. 18 (57). - № 2. С. 88-96.

15. Петренко Р. А. Многоаспектность понятий «агрессия» и «агрессивность» // Гуманитарные и социальные науки. - 2010. - № 5.

16. Петренко Р. А., Гетманов И. П., Кимстач В. Н. Биологические и социокультурные факторы агрессии: учебное пособие. - Новочеркасск, 2008. - С. 8-9.

17. Попова Н. К., Плюснина И. 3., Науменко В. С. Участие серотониновых 5-НТ1А-рецепторов мозга в генетической предрасположенности к агрессивному поведению // Журнал высшей нервной деятельности им. И. П. Павлова. - 2006. - № 4. - С. 537-542.

18. Реан А. А. Агрессия и агрессивность личности // Психологический журнал. - 1996. - № 5.

19. Реан А. А. Психология личности. Социализация, поведение, общение. СПб.: Прайм-Еврознак, 2004. - 407 с.

20. Ребер А. Большой толковый психологический словарь. - М.: 2001. - Т. 1.

21. Тиходеев О. Н. Основы психогенетики:учебник для студ. учреждений высш. проф. образования. - М.: Издательский центр «Академия», 2011. - 320 с.

22. Фромм Э. Анатомия человеческой деструктивности. Пер. с нем. - М.: ACT, 2006. - 640 c. 
23. Чистякова Н. В., Сергиенко Е. А. Генотип-средовое взаимодействие: молекулярно-генетический подход к изучению волевого контроля в период беременности // Российский психологический журнал. 2012. - T. 9. - № 4. - С. 22-33.

24. Шабалин О. М. Агрессивность как комплексная характеристика индивидуальности // Психопедагогика в правоохранительных органах. 2008. - № 2 (33). - С. 33-35.

25. Шустикова М. В. Генетические и средовые детерминанты агрессивного поведения // Вестник Харьковского национального университета им. В. Н. Каразина. Серия: Биология. - 2005. - Вып. 1-2. - № 709. C. 111-115.

26. Birger M., Swartz M., Cohen D. et al. Aggression: the testosterone-serotonin link // Isr. Med. Assoc. J. - 2003. - no. 5. - pp. 653-658.

27. Cates D. S., Houston B. K., Vavak C. R. et al. Heritability of hostility-related emotions, attitudes, and behaviors // JBehavMed, 1993. - no. 16. pp. 237-256.

28. Coccaro E. F., Bergerman C., Kavoussi R. J., Seroczynski A. Heritability of aggression and irritability: a twin study of the Buss-Durkee Aggression Scales in adult male subjects // Biol Psychiatry. - 1997 b. - V. 41. - no. 3. pp. 273-284.

29. Comings D. E., Muhleman D. V., Gysin R. Dopamine D2 receptor (DRD2) gene and susceptibility to posttraumatic stress disorder: A study and replication // Biol. Psychiatry. - 1996. - V. 40. - no. 5. - pp. 368-372.

30. Dabbs J. M., Morris R. Testosterone, social class, and antisocial behavior in a sample of 4.462 men // Psychol. Sci. - 1990. - no. 1. - pp. 209-211.

31. Davidson R. J., Putnam K. M., Larson C. L. Dysfunction in the neural circuitry of emotion regulation - a possible prelude to violence // Science. - 2000. no. 289. - pp. 591-594.

32. Ermakov $P$. Hemispheric asymmetry of aggressive behavior and hereditary factors // International Journal of Psychophysiology. - 2014. - no. 2. - P. 143.

33. Ermakov P. N., Abakumova I. V. Youth against terrorism (on the work of the anti-terrorist youth festival) // Russian Psychological Journal. - 2012. - V. 9. no. 4. - pp. 11-15.

34. Ermakov P. N., Michailova O. U. The study of the disorders of hemispheric balance in multiepisode criminals // Int. J. Psychophysiology. Absrt. of the 9th World Congress of the IOP, Italy, Sept. - 1998. - V. 30. - № 1-2. pp. 220-221.

35. Kriks S., Shim J. W., Piao J. Dopamine neurons derived from human ES cells efficiently engraft in animal models of Parkinson's disease // Nature. - 2011. V. 480 (7378). - pp. 547-551. 
36. Kulikov A. V., Osipova D. V., Naumenko V. S. et al. A pharmacological evidence of positive association between mouse intermale aggression and brain serotonin metabolism // Behav. Brain Res. - 2012. - V. 233. - no. 1. - pp. 113-119.

37. Lein E. S., Hawrylycz M. J., Ao N. Et al. Genome-wide atlas of gene expression in the adult mouse brain // Nature. - 2007. - V. 445 (7124). - pp. 168-176.

38. Mayer Bahlburg H. F. L. Sex chromosomes and aggression in humans / by ed. Brain P. P., Benton D. // The biology of aggression. - Rockville: MD, 1981. pp. 109-123.

39. Middeldorp C. M., de Geus E. J., Willemsen G. et al. The serotonin transporter gene length polymorphism (5-HTTLPR) and life events: no evidence for an interaction effect on neuroticism and anxious depressive symptoms // Twin Res Hum Genet. - 2010. - V. 13. - no. 6. - pp. 544-549.

40. Naumenko V. S., Kondaurova E. M., Popova N. K. On the role of brain 5-HT7 receptor in the mechanism of hypothermia mediated via 5-HT1 A and 5-HT3 receptor // Neuropharmacology. - 2011. - V. 61. - no. 8. - pp. 1360-1365.

41. Nimgaonkav V. L. et al. Psychosis and aggression associated with dopamine receptor gene polymorphisms in Alzheimer's disease // Am. J. Med. Genet. 1997. - V. 74. - no. 6. - P. 627.

42. Popova N. K., Voitenko N. N. Brain serotonin metabolism in hibernation // Pharmacol Biochem Behav. - 1981. - V. 14. - no. 6. - pp. 773-777.

43. Siegel A., Victoroff J. Understanding human aggression: New insights from neuroscience // Int. J. Law Psychiatry. - 2009. - no. 32. - pp. 209-225.

44. Stalenheim E. G., Eriksson E., Knorring L von, Wide L. Testosterone as a biological marker in psychopathy and alcoholism // Psychiatr. Res. - 1998. - no. 77. pp. 79-88.

45. Staner L., Mendlewicz J. Heredity and role of serotonin in aggressive impulsive behavior // Encephale. - 1998. - no. 24. - pp. 355-364.

46. Tsai S. J. et al. Association study of serotonin-6 receptor variant (C 267 T) with schizophrenia and aggressive behavior // Neurosci. Lett. - 1999. V. 271. - pp. 135-137.

47. Vasiliev G. V., Merkulov V. M., Kobzev V. F. Point mutations within 663-666 bp of intron 6 of the human TDO2 gene, associated with a number of psychiatric disorders, damage the YY-1 transcription factor binding site // FEBS Lett. - 1999. - V. 462. - no. 1-2. - pp. 85-88.

48. Vetulani J. Neurochemistry of impulsiveness and aggression // Psychiatria Polska. - 2013. - V. XLVII. - no. 1. - pp. 103-113.

49. Yeh M. T., Coccaro K., Jacobson C. Multivariate behavior genetic analyses of aggressive behavior subtypes // Behav. Genet. - 2010. - V. 40. pp. 603-617. 
dokladov [XXII Congress of Physiological Society named I. P. Pavlov: Abstracts]. Volgograd, VolgGMU Publ., 2013, pp. 619-620.

10. Arden R., Chavez R. S., Grazioplene R., Jung R. E. Neuroimaging creativity: A psychometric view // Behavioural Brain Research, 2010, V. 214, pp. 143-156.

11. Dikaya L. A., Dikiy I. S. Brain correlates of composing major and minor music // International Journal of Psychology. Special Issue: XXX International Congress of Psychology, 2012, V. 47, Supp. 1, P. 113.

12. Dikaya L. A., Ermakov P. N., Dikiy I. S. EEG correlates of professional creative problem solving with insight // International journal of psychophysiology, 2012, V. 85, Issue 3, P. 379.

13. Fink A., Graif B., Neubauer A. C. Brain correlates underlying creative thinking: EEG alpha activity in professional vs. novice dancers // Neuroimage, 2009, V. 46 (3), pp. 854-862.

14. Jung-Beeman M., Bowden E. M., Haberman J., Frymiare J. L., Arambel-Liu S., Greenblatt R. et al. Neural activity when people solve verbal problems with insight // PLoS Biology, 2004, V. 2 (4), pp. 500-510.

15. Sheth B. R., Sandkuhler S., Bhattacharya J. Posterior beta and anterior gamma oscillations predict cognitive insight // Journal of Cognitive Neuroscience, 2009, V. 21 (7), pp. 1269-1279.

16. Starchenko M. G., Bekhtereva N. P., Pakhomov S. V., Medvedev S. V. Study of the brain organization of creative thinking // Human Physiology, 2003, V. 29 (5), pp. 652-653.

\title{
THE REVIEW OF MODERN RESEARCHES OF PSYCHOGENETIC FACTORS OF AGGRESSIVE BEHAVIOR
}

\author{
Kovsh Ekaterina Mikhailovna \\ Vorob'eva Elena Viktorovna \\ Ermakov Pavel Nikolaevich
}

The review covers urgent domestic and foreign researches of psychogenetic factors of aggressive behavior. The authors consider cytogenetic mechanisms providing mental activity and behavioural activity of the person, offer the concept of the control system of information coding, and specify features of a genotype-environmental interaction in forming aggressive behavior. Classification of forms of aggression is given. Approaches to interpretation of this concept are considered. The theories explaining the nature of aggression (J. Dollard and L. Berkowitz's frustration theory, A. Bandura's theory of social 
learning, K. Lorentz and S. Freud's theory of instinctual drives, biological theory) are analyzed. The brain mechanisms underlying different forms of aggressive behavior are described.

A large number of domestic and foreign studies devoted to the problem of genetic determination of mental processes and behavior is analyzed. The authors bring forward the review of researches of genetic foundations of aggressive behavior. They describe approaches recognized insolvent today (the extra Y-chromosome theory, the "genesign" system, the "generalist genes" concept) and offer conceptions confirmed today: the role of monoamine neuromodulators (the interrelation between various forms of aggressive behavior and neurotransmitter systems of the brain), testosterone is described; the influence of the social-economic status and the environmental factors is considered. The available psychogenetic data is described from the point of view of the additive model of development. On the whole, they note a polygenic nature of the inheritance of aggression (the genes coding information of the olfactory, hormonal, mediator systems are biological factors of aggression).

Perspectives of the development of this research area are outlined: the bioinformation analysis of molecular mechanisms of activity of the central nervous system by means of studying the expression of genes in brain cells; the review of the first results obtained by means of this method is offered.

Keywords: psychogenetics of aggression, neurotransmitter systems, monoamines, genetics of behavior, molecular genetics, aggressive behavior, aggression, biological substrate, brain mechanisms, chromosomal anomalies, genotype-environment correlation.

\section{References}

1. Alfimova M. V., Trubnikov V. I. Gennye osnovy temperamenta i lichnosti [Genetic basis of temperament and personality]. Voprosy psihologii Approaches to Psychology, 2000, no. 2, pp. 15-118.

2. Alfimova M. V., Trubnikov V. I. Psihogenetika agressivnosti [Psychogenetic basis of aggressiveness]. Voprosy psihologii - Approaches to Psychology, 2000, no. 6, pp. 112-123.

3. Bondarenko V.V., Vorob'eva E. V. Istorija formirovanija bliznecovogo metoda v psihologii [The history of the formation of the twin method in psychology]. Severo-Kavkazskij psihologicheskij vestnik - North-Caucasian Psychological Bulletin, 2006, no. 4, pp. 151-153.

4. Baron R., Richardson D. Agressija [Aggression]. St. Petersburg, Piter Publ., 2001, 352 p.

5. Vorob'eva E. V. Intellekt i motivacija dostizhenija: psihofiziologicheskie i psihogeneticheskie prediktory [Intelligence and motivation to achieve: physiological and psychogenetic predictors]. Moscow, KREDO Publ., 2006, 288 p.

6. Vorob'eva E. V. Psihogeneticheskoe issledovanie vzaimosvjazi temperamenta i motivacii dostizhenija [Psychogenetic study of the relationship between 
temperament and motivation to achieve]. Izvestija vysshih uchebnyh zavedenij. Severo-Kavkazskij region. Obshhestvennye nauki-News of higher educational institutions. The North Caucasus region. Social Sciences, 2006, no. 3, pp. 110-111.

7. Connor D. Agressija i antisocial'noe povedenie u detej i podrostkov. Issledovanija i terapevticheskie strategii [Aggression and antisocial behavior in children and adolescents. Research and therapeutic strategies]. Moscow, Olma-media grupp Publ., 2005, 286 p.

8. Kudrjavceva N. N. Agressija: ot koncepcii K. Loranca k sovremennym predstavlenijam [Aggression: from the conception of K. Lorenz to modern views]. Priroda - Nature, 2008, no. 9, pp.60-63.

9. Levin Ja. I. Nejrohimicheskaja medicina. Chast' 1. Cerebral'nye dofaminergicheskie sistemy [Neurochemical medicine. Part 1. Cerebral dopaminergic systems]. Sovremennaja terapija psihicheskih rasstrojstv - The modern treatment of mental disorders, 2008, no. 1.

10. Mesherjakov B. G., Zinchenko V. P. Bol'shoj psihologicheskij slovar' [The great psychological dictionary]. St. Petersburg, Prime Evroznak Publ., 2006, $672 \mathrm{p}$.

11. Mihajlova O. Ju. Psihologicheskie mehanizmy kriminal'noj seksual'noj agressii [Psychological mechanisms of criminal sexual aggression]. Diss. ... Doct. psychol. science. Rostov n/D., 2001.

12. Mihajlova T. I. Psihogeneticheskie predposylki agressivnosti [Psychogenetic prerequisites of aggressiveness]. Vestnik SumDU, Serija "Medicina" - SumDU Bulletin, a series of "Medicine", 2012, no. 1.

13. Orlov Ju. L., Vishnevskij O. V., Vitjaev E. E. et al. Bioinformacionnyj analiz jekspressii genov v kletkah mozga [Bioinformatics analysis of gene expression in brain cells]. Materialy XV Vserossijskoj nauchno-tehnicheskoj konferencii "Nejroinformatika-2013" - The materials of the XVth all-Russian scientifictechnical conference "Neuroinformatics-2013", Moscow, 2013.

14. Pavlenko V. B., Kalashnik O. A. Nejrojetologija i nejrofiziologicheskie korreljaty agressivnosti [Neuroethology and neurophysiological correlates of aggression]. Uchenye zapiski Tavricheskogo nacional'nogo universiteta im. V. I. Vernadskogo - Scientific notes of Tauride National University behalf of V. I. Vernadsky, 2005, V. 18 (57), no. 2, pp. 88-96.

15. Petrenko R. A., Getmanov I. P., Kimstach V. N. Biologicheskie i sociokul'turnye faktory agressii: uchebnoe posobie [Biological and socio-cultural factors of aggression]. Novocherkassk, 2008, pp. 8-9.

16. Petrenko R. A. Mnogoaspektnost'ponjatij "agressija"i iagressivnost"' [The multidimensionality of the terms "aggression" and "aggressiveness"]. Gumanitarnye i social'nye nauki - Humanities and social Sciences, 2010, no. 5. 
17. Popova N. K., Pljusnina I. Z., Naumenko V. S. Uchastie serotoninovyh 5-NT1Areceptorov mozga $v$ geneticheskoj predraspolozhennosti k agressivnomu povedeniju [Participation of brain serotonin 5-HT1A-receptors in the genetic predisposition to aggressive behavior]. Zhurnal vysshej nervnoj dejatel'nosti im. I. P. Pavlova - Journal of higher nervous activity behalf of I. P. Pavlov, 2006, no. 4, pp. 537-542.

18. Rean A. A. Agressija i agressivnost'lichnosti [Aggression and aggressiveness of personality]. Psihologicheskij zhurnal - Psychological Journal, 1996, no. 5.

19. Rean A. A. Psihologija lichnosti. Socializacija, povedenie, obshenie [Personality psychology. Socialization, behavior, communication]. St. Petersburg, PrimeEvroznak Publ., 2004, 407 p.

20. Reber A. Bol'shoj tolkovyj psihologicheskijslovar' [Big explanatory psychological dictionary]. Moscow, 2001, V. 1.

21. Tihodeev N. Osnovy psihogenetiki: uchebnik dlja stud. uchrezhdenij vyssh. prof. obrazovanija [Fundamentals of psychogenetics]. Academy Publ., 2011, 320 p.

22. Fromm E. Anatomija chelovecheskoj destruktivnosti. Per. s nem. [The anatomy of human destructiveness]. Moscow, AST Publ., 2006, 640 p.

23. Chistjakova N. V., Sergienko E. A. Genotip-sredovoe vzaimodejstvie: molekuljarno-geneticheskij podhod k izucheniju volevogo kontrolja v period beremennosti [Genotype-environment interaction: molecular-genetics approach to the study of voluntary control during pregnancy]. Rossijskij psihologicheskij zhurnal - Russian psychological journal, 2012, V. 9, no. 4, pp. 22-33.

24. Shabalin O. M. Agressivnost'kak kompleksnaja harakteristika individual'nosti [Aggressiveness as a comprehensive description of personality]. Psihopedagogika v pravoohranitel'nyh organah - Psychopedagogy in law enforcement, 2008, no. 2 (33), pp. 33-35.

25. Shustikova M. V. Geneticheskie i sredovye determinanty agressivnogo povedenija [Genetic and environmental determinants of aggressive behavior]. Vestnik Har'kovskogo nacional'nogo universiteta im. V. N. Karazina. Serija:Biologija - Bulletin of Kharkov national University behalf of V. N. Karazin. Series: Biology, 2005, V. 1-2, no. 709, pp. 111-115.

26. Birger M., Swartz M., Cohen D. et al. Aggression: the testosterone-serotonin link // Isr. Med. Assoc. J., 2003, no. 5, pp. 653-658.

27. Cates D. S., Houston B. K., Vavak C. R. et al. Heritability of hostilityrelated emotions, attitudes, and behaviors // JBehavMed, 1993, no. 16, pp. 237-256.

28. Coccaro E. F., Bergerman C., Kavoussi R. J., Seroczynski A. Heritability of aggression and irritability: a twin study of the Buss-Durkee Aggression Scales in adult male subjects // Biol Psychiatry, 1997 b, V. 41, no. 3, pp. 273-284. 
29. Comings D. E., Muhleman D. V., Gysin R. Dopamine D2 receptor (DRD2) gene and susceptibility to posttraumatic stress disorder: A study and replication // Biol. Psychiatry, 1996, V. 40, no. 5, pp. 368-372.

30. Dabbs J. M., Morris R. Testosterone, social class, and antisocial behavior in a sample of 4.462 men // Psychol. Sci., 1990, no. 1, pp. 209-211.

31. Davidson R. J., Putnam K. M., Larson C. L. Dysfunction in the neural circuitry of emotion regulation - a possible prelude to violence // Science, 2000, no. 289, pp. 591-594.

32. Ermakov P. Hemispheric asymmetry of aggressive behavior and hereditary factors // International Journal of Psychophysiology, 2014, no. 2, pp. 143.

33. Ermakov P. N., Abakumova I. V. Youth against terrorism (on the work of the anti-terrorist youth festival) // Russian Psychological Journal, 2012, V. 9, no. 4, pp. 11-15.

34. Ermakov P. N., Michailova O. U. The study of the disorders of hemispheric balance in multiepisode criminals (тезисы) // Int. J. Psychophysiology. Absrt. of the 9th World Congress of the IOP, Italy,Sept., 1998, V. 30, № 1-2, pp. 220-221.

35. Kriks S., Shim J. W., Piao J. Dopamine neurons derived from human ES cells efficiently engraft in animal models of Parkinson's disease // Nature, 2011, V. 480 (7378), pp. 547-551.

36. Kulikov A. V., Osipova D. V., Naumenko V. S. et al. A pharmacological evidence of positive association between mouse intermale aggression and brain serotonin metabolism // Behav Brain Res, 2012, V. 233, no. 1, pp. 113-119.

37. Lein E. S., Hawrylycz M. J., Ao N. Et al. Genome-wide atlas of gene expression in the adult mouse brain // Nature, 2007, V. 445(7124), pp. 168-176.

38. Mayer Bahlburg H. F. L. Sex chromosomes and aggression in humans / by ed. Brain P. P., Benton D. // The biology of aggression. Rockville: - MD, 1981, pp. 109-123.

39. Middeldorp C. M., de Geus E. J., Willemsen G. et al. The serotonin transporter gene length polymorphism (5-HTTLPR) and life events: no evidence for an interaction effect on neuroticism and anxious depressive symptoms //Twin Res Hum Genet, 2010, V. 13, no. 6, pp. 544-549.

40. Naumenko V. S., Kondaurova E. M., Popova N. K. On the role of brain 5-HT7 receptor in the mechanism of hypothermia mediated via 5-HT1A and 5-HT3 receptor // Neuropharmacology, 2011, V. 61, no. 8, pp. 1360-1365.

41. Nimgaonkav V. L. et al. Psychosis and aggression associated with dopamine receptor gene polymorphisms in Alzheimer's disease // Am. J. Med. Genet, 1997, V. 74, no. 6, P. 627.

42. Popova N. K., Voitenko N. N. Brain serotonin metabolism in hibernation // Pharmacol Biochem Behav, 1981, V. 14, no. 6, pp. 773-777. 
43. Siegel A., Victoroff J. Understanding human aggression: New insights from neuroscience // Int. J. Law Psychiatry, 2009, no. 32, pp. 209-225.

44. Stalenheim E. G., Eriksson E., Knorring L von, Wide L. Testosterone as a biological marker in psychopathy and alcoholism // Psychiatr. Res., 1998, no. 77, pp. 79-88.

45. Staner L., Mendlewicz J. Heredity and role of serotonin in aggressive impulsive behavior // Encephale, 1998, no. 24, pp. 355-364.

46. Tsai S. J. et al. Association study of serotonin-6 receptor variant (C 267 T) with schizophrenia and aggressive behavior // Neurosci. Lett, 1999, V. 271, pp. 135-137.

47. Vasiliev G. V., Merkulov V. M., Kobzev V. F. Point mutations within 663-666 bp of intron 6 of the human TDO2 gene, associated with a number of psychiatric disorders, damage the YY-1 transcription factor binding site // FEBS Lett, 1999, V. 462, no 1-2, pp. 85-88.

48. Vetulani J. Neurochemistry of impulsiveness and aggression // Psychiatria Polska, 2013, V. XLVII, no. 1, pp. 103-113.

49. Yeh M.T., Coccaro K., Jacobson C. Multivariate behavior genetic analyses of aggressive behavior subtypes // Behav. Genet., 2010, V. 40, pp. 603-617.

\section{COGNITIVE-STYLE FACTORS OF DEFENSIVENESS OF SCHIZOPHRENIC PATIENTS}

\section{Kulikova Ol'ga Sergeevna}

The article deals with the problem of social adaptation of patients with the initial stage of paranoid schizophrenia; mechanisms of psychological defense directed on decreasing anxiety are considered as important forms of adaptation behavior of patients with paranoid schizophrenia; certain features of the cognitive sphere are at the basis of psychological defense. The author calls attention to a brief literature review of views of the nature of these cognitive features. On this evidence in the article they experimentally test a thesis that features of the cognitive-style sphere are the basis of choosing and activization of one or another form of psychological defense of patients with paranoid schizophrenia. This aspect of considering interrelation of a cognitive style and psychological defense is not reflected in domestic and foreign sources.

The author has examined 80 patients with paranoid schizophrenia (with disease duration no more than a year); all the patients were in medicated remission at the moment of examination. For realization of research objectives the author has used 